\title{
Real Options for risk analysis in estimating the capitalization rate
}

\author{
Pierluigi Morano \\ Science Department of Civil Engineering and Architecture \\ Polytechnic of Bari \\ Bari, Italy \\ p.morano@poliba.it
}

\author{
Benedetto Manganelli \\ Department of Architecture, Planning and Transport \\ Infrastructure \\ University of Studies of Basilicata \\ Potenza, Italy \\ benedetto.manganelli@unibas.it
}

\author{
Francesco Tajani \\ Department of Civil Engineering \\ University of Studies of Salerno \\ Fisciano, Italy \\ ftajani@unisa.it
}

\begin{abstract}
A suitable cap-rate is generally determined through an analogical process in order to estimate the value of any real estate through the capitalization of the incomes. The analogy relates to the risk and duration of similar investments. There are numerous methods to rationalize the valuation of the cap-rate. Appraisals have a certain degree of uncertainty in all these methods. This paper proposes a methodology which removes any uncertainty when evaluating the cap-rate. This is achieved through the combination of the formal logic of the Ellwood's model and the Real Options Analysis.
\end{abstract}

Keywords-Ellwood, real options, cap rate, risk analysis.

\section{INTRODUCTION}

When the estimation of the market value of property is based on the capitalization of income, the choice of capitalization rate can be made through different procedures. The analogical procedure, which is the most widely adopted, is usually a comparison between an assumed return rate on investments similar to those of the property to be evaluated. The analogy specifically concerns two aspects: the risk and duration of the investment. The assumed rate must be correctly defined, either up or down, in order to take into account the differences between investment risk and the different role played by the return rate in relation to the function of the capitalization rate.

In current literature, there is an ample discussion on the procedures that are intended to streamline the estimation by analogy of the capitalization rate $[1,7,12,15,18]$. In all cases, however, there still remains a rate of uncertainty that significantly affects the final estimation of the property. This is due to the inverse relationship that ties the rate to the result of the estimation, so that - as it is well-known - a slight change, increasing or decreasing, of the capitalization rate corresponds to significant inverse variations in the estimations.

\section{AIM AND OBJECTIVES}

The aim of this work is to reduce the uncertainty inherent in estimating the capitalization rate by converting it into risk. This paper is a generalization of the appraisal model of the capitalization rate already developed for the Italian market [18].

The reduction of the uncertainty is achieved by combining the logic at the bases of the Ellwood model and Real Options Analysis (ROA), with the main references being discussed in the following paragraphs. For a more detailed discussion, see the studies cited in the bibliography. In detail, the property investment pattern of the Ellwood model, obtained from the sequence of the financial income and expenses related to the established availability period of the property, combined with the risk analysis of the ROA, makes it possible to anticipate the evolution of the investment value up to the year in which it is convenient to recover the initial capital.

The choices derived from the analysis carried out and the verification of the reliability of the model that is proposed are made via the implementation of the model to the estimation of the market value of the properties that make up a sample of the study as well as the subsequent measurement error. The result is a capitalization rate that has value on a broad area identified - for example - with the centre or the periphery of a city. Accordingly, this rate should be corrected when having to take into account both the effects of specific factors of the area as well as the intrinsic characteristics of the property subject of the estimation. 


\section{SIGNS OF THE ELLWOOD MODEL AND REAL OPTIONS} ANALYSIS

In the Ellwood model, the capitalization rate is sought from the equation that adds up the assets and the liabilities of a typical property investment [10]. In this model, the revenues and expenditures, due to being attributable at different times, become financially homogeneous through the reduction of the amounts of individual items to year zero by using the internal return rate of the property investment.

From the financial analysis, the capitalization rate is then derived as the relationship between the ordinary producible income from the property and the estimated value of the property.

Real Options Analysis (ROA) is a technique for estimating investments that can be successfully used to manage the uncertainty related to possible changes of scenario $[5,8]$.

Compared to the static approach, which considers the updating of cash flow of the future investment for the most likely scenario, ROA, where the uncertainty can be transformed into risk, makes it possible to carry out a risk analysis of the various project solutions, called options [19].

There are multiple analytical formulations of the ROA. In this work, the binomial paradigm is used [4], which develops the changes of the initial values of the investment through multiplicative probability, defined by the coefficients $u>1$ and $d<1$, which represent, respectively, the evolution of the initial state towards either a favourable or unfavourable scenario.

The size of the coefficients $u$ and $d$ is the result of the investment risk analysis, statistically calculated by a dispersion index that, in the case of a normal distribution of the variable under analysis, coincides with its standard deviation $(\sigma)$.

Having estimated the risk, the definition of the possible evolution states occurs with the mathematical expressions in (1):

$$
\left\{\begin{array}{l}
u=e^{\sigma \cdot \sqrt{d t}} \\
d=e^{-\sigma \cdot \sqrt{d t}}
\end{array}\right.
$$

where:

$e=$ Napier number;

$\sigma=$ standard deviation, also called - in ROA - volatility;

$d t=$ considered time interval between the successive scenario evolutions.

With the use of the coefficients $u$ and $d$, the initial investment has a typical tree-like structure (scenario tree), derived from the analysis grid [6].

A decision tree is built after the risk analysis $[11,16]$. This is the stage where feasible options are identified and the corresponding values quantified. The valorisation of the inherent options of a project makes it possible to identify the "managerial flexibility and adaptability" that the decision maker can use $[14,17]$. The decision tree makes it possible to measure the impact, on the financial analysis, of the possible development options of the investment. The impact measurement requires the preliminary definition of a maximization function, which conforms to the particular type of option identified. With this function, in the year when the option is exercised and for every possible scenario in that year, the comparison of the present value of the investment "with" and "without" the option is carried out.

The operation described is performed for all the $n$ scenarios of the year of feasibility of the option, making it possible to establish a vector of the majors, of dimension $n x l$, which is then discounted to the current scenarios following the scenario tree from right to left. The calculation is performed by weighting the elements of the vector with the coefficients of risk-neutral probabilities ( $p$ and 1-p), relating to the current situation, the outcome of the weights using a discount rate $\left(r_{i}\right)$.

The result is the present extended value of the investment, a value that includes the effect of the option or options that may be exercised.

\section{THE BASIC ASSUMPITIONS}

One hypothesis is that the property is purchased with the entire sum. This eliminates three variables from the termination equation of the financial analysis of the Ellwood model: the partially financed capital, the interest rate for the recovery of the loan, as well as the duration of the depreciation period. The eligibility of the simplification is due to the low influence that the three variables have on the final result, especially when not determining the performance of a property investment, but rather a capitalization rate.

Another hypothesis assumes that the availability period of the property, due to it deriving from the construction and solution of a maximisation function of the profits generated by the investment, is an endogenous variable of the model. In fact, the maximization of profits is a primary objective of any economic entity that decides to invest capital, and therefore also of an ordinary investor. The maximisation function used in the model implements the risk analysis of the investment.

Another possibility includes the invariability of income [13]. In fact, as confirmed through the application of the model to several case studies, the duration of the investment is roughly equal to the normal length of a lease. A study on how the effects of macroeconomic factors have been generated on the economic cycles of the housing market of four California cities [9] showed that leases complicate the transmission mechanism of any shocks to the external application (such as an unexpected growth in employment) on the values of the lease. The contracts determine the rental market, a significant delayed impact compared to the effect felt on real estate transactions. These contracts do not include the variability of the agreed income, thus, it is to be expected that, at the end of the availability period of the property, the actual rent (i.e. based on the invariability of prices) remains constant.

The implemented risk analysis objectifies the estimation of the capitalization rate, eliminating the remaining uncertainties in the definition of the capital property appreciation rate as well as the discount rate in the financial analysis. The 
assumption is that the riskiness of the property investment can be explained by the volatility of the time series of the annual rates of appreciation or depreciation of property values. The time series of the rates can be constructed from the annual average property values for the cities and in homogeneous areas, provided by databases for sufficiently long periods, which are therefore statistically significant. The use of verification tests has highlighted that the distribution of the time series of the annual rates observed in many Italian cities agrees with good approximation to the assumption of normal development, required for the development following the analyses.

The volatility of the series of the appreciation or depreciation rates of property values, or the investment risk, may therefore be represented in an effective measurement of its standard deviation $(\sigma)$, calculated as a percentage of the average in the series.

\section{DESCRIPTION OF THE MODEL}

In its formal and logical articulation, the new model is defined by five equations, presented in Table I.

On the basis of the aforementioned assumptions, the Ellwood financial statement for a property investment can be written using (2) in which appear, the first term, the revenues from the investment during the availability period of the property $(m)$, obtained from the sum of the deferred and constant annual incomes $(R)$ and increased by the property value at the end of the availability period (projection period), consisting of the purchase price $(P)$ re-evaluated with the coefficient $r_{v}$. All the items of the first term are discounted at a rate $\left(r_{i}\right)$. The second term is given by the initial investment cost $(K)$, consisting of the purchase price of the property, the brokerage fees and associated costs of ownership transfer.

TABLE I. EQUATIONS THAT DESCRIBE THE MODEL

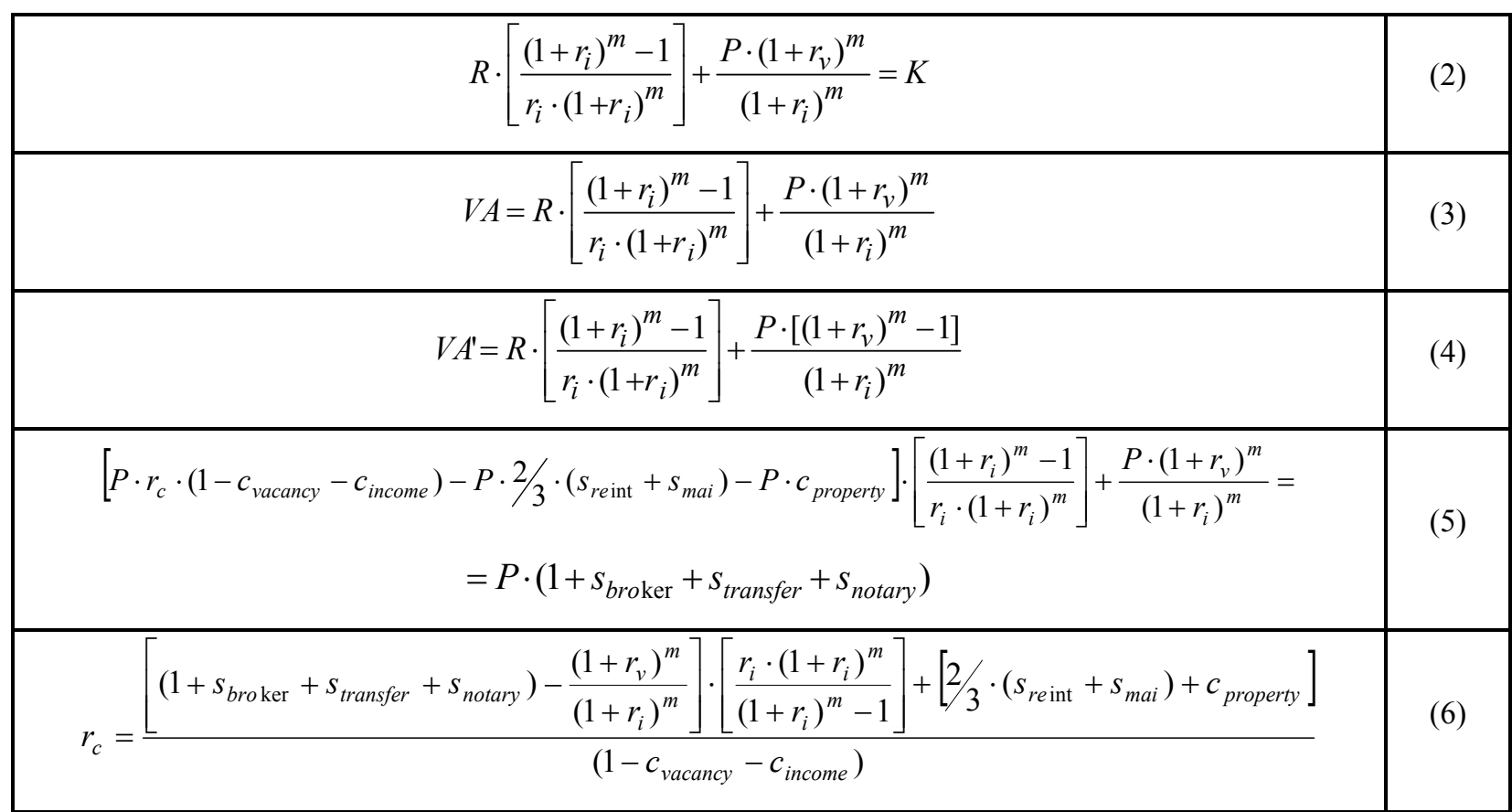

In the binomial system adopted for the analysis of the real options, once the standard deviation $(\sigma)$ and the parameters $u$ and $d$ have been estimated, the stochastic evolution of the present value of the investment (VA) is defined. As reported in Table I, this evolution coincides with the first member of (2) and can be written using (3).

It should be noted that the purchase price $(\mathrm{P})$ of the property - also present in (3) - is a constant whose exclusion from the calculation does not produce errors in the probabilistic evolution of the investment which can be set out in the scenario tree, but it simplifies some mathematical manipulations. Therefore, in Eq. 4, the value of the current year estimate (VA') is set equal to the sum of real financial cash flow (gross income generated from the rental of the property) and virtual flows (annual revaluation or depreciation of the capital). The latter being flows which are so called because they are not collected every year, but gradually accumulate in the residual value that is received in year $\mathrm{m}$ of mobilization of the investment.

For the construction of the scenario tree based on the binomial approach, we assume that all the parameters of (4) are known, with the exception of the availability period of the property $(m)$. On this condition, it is possible to show that, given the option for which the sale will be exercised in the year in which the option itself will be more cost effective, there is a unique relationship between the volatility value of the investment $(\sigma)$ and the availability period of the property $(m)$, to offset the uncertainty related to the identification of the projection period. The demonstration has calculated the present value of the cash flows in the first year, then the second, then third and so on, assuming that the option of 
selling the property, is carried out in a worst situation, i.e. along the branch of the worst evolution of the property investment. The calculation shows that, for a given volatility value, the $d^{i} V A$ ' value of the investment - obtained from the most pessimistic scenario, by gradually increasing $m-$ has a trend that uniquely defines a maximum value.

Fig. 1 shows the change in the $d^{i} V A^{\prime}$ 'value for the different volatility values, assigning the parameters of (4) with reference to a case study. Using a simple algorithm that expresses the maximization function of the profits achieved from that investment, there is the maximum of the function, or the maximum $d^{i} V A^{\prime}$ and the corresponding year $\mathrm{m}$ of the disposal of the property.

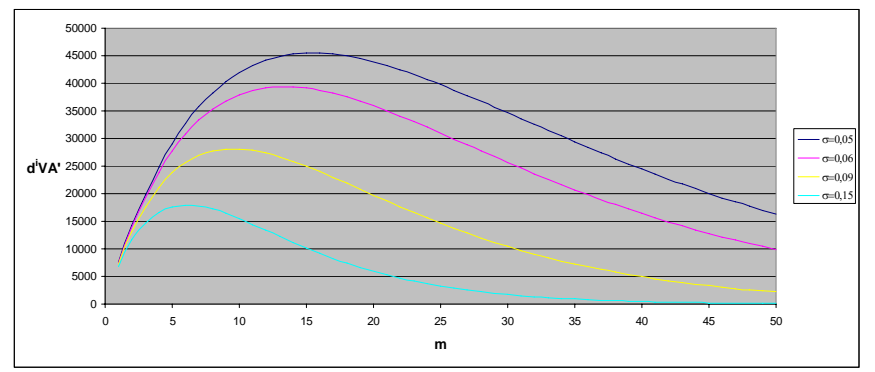

Fig. 1. Development of the $d^{i} V A^{\prime}$ value varying volatility $(\sigma)$

Built with the same data as Fig. 1, Fig. 2 shows that the relationship between $\sigma$ and $m$ is consistent with the expectations so that, for an increase of $\sigma$, and hence the riskiness of the investment, there is a reduction of the availability period of the property. Chu and Sing [2] have highlighted that in the property market, investors are contrary to exercising the deferment in light of possible future developments, when there are concrete and actual conditions that threaten the expected revenues in the short-term.

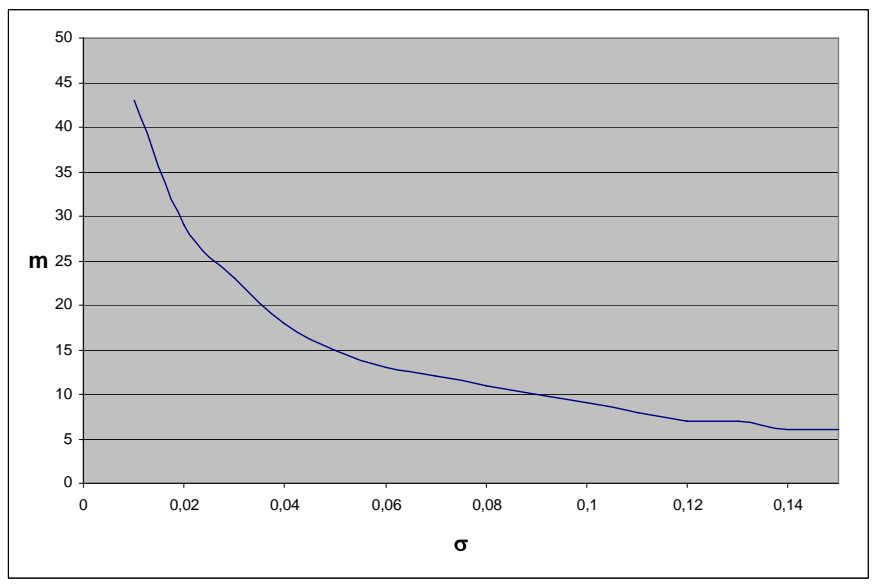

Fig. 2. Relationship between the availability period (m) and volatility ( $\sigma$ )

Analysing the evolutionary path described by the branch of the scenario tree immediately above the most pessimistic one $\left(u d^{i-1} V A^{\prime}\right)$, it can be noted that the year in which the exercising of the option to allow for the sale with maximum profits is not different. Similarly, when analysing the branches of the tree, the paths that describe progressive evolutions of more favourable scenarios $\left(u^{2} d^{i-2} V A^{\prime}, u^{3} d^{i-3} V A^{\prime}, u^{4} d^{i-4} V A^{\prime}, ..\right)$, there is always the same year $m$ that is more convenient to dispose of the investment. Year $m$ is therefore the time when, regardless of the more or less favourable scenario, the property should be sold. To confirm the consistency of the binomial paradigm, the same result is reached in the continuing development of the mathematical decision tree by placing the sale to year $m$ as a particular option. This option is characterized by the maximization of a function that compares the value of the flow $V A$ ' to year $\mathrm{m}$, found for all possible scenarios $(m+1)$, with the same amount of initial capital $(P)$. Capital that becomes available again at the end of the projection period $(m)$, year uniquely identified by the volatility of the investment. In fact, it is to the year $m$ that consolidates the present value of "total" of the investment property, given that the sum includes the financial cash flows and the amount corresponding to the recovery of the purchase price, namely the capital invested. Considering the values of year $m$ with the probability $p$ and $1-p$, modified according to the sale of the property, or the exercising of the particular option, and discounting the values weighted to the present by the rate $r_{i}$, the present value of the investment to the year zero ( $V A$ ' extended) becomes equal to the present value of the investment property as it appears in the sale of the property in year $m$ in the absence of options.

Due to the results described and having fixed the costeffectiveness as the sole criterion for defining the year of disposal of the investment, the sale cannot be treated as a real option. In fact, an option may be defined as the ability of the decision maker to exercise a choice under certain evolutionary conditions, choice upon which the analysis of real options is able to assign a value. In the analysis carried out, however, the sale in year $m$ does not have a more convenient alternative scenario or branch of the tree. Therefore, it is a requirement, for the normal investor, to sell in that year. This creates the return to (3) after determining, as described, the year $m$.

In (2), it is possible to make the expenses of the main part explicit, in order to obtain, from the rent, the net income and the initial investment costs $(K)$.

The gross capitalization rate $\left(r_{c}\right)$ is defined as the relationship between the rent $(\mathrm{Ca})$ and the purchase price of the property $(P)$. The balance sheet of (2) can be rewritten with (5), with the taxes and expenses being listed in Table II. 
TABLE II. TAXES AND EXPENSES IN EQUATIONS OF TABLE I

\begin{tabular}{|c|c|}
\hline$c_{\text {vacancy }}$ & percentage of losses due to vacancy and write-offs ( $\%$ of $R$ ) \\
\hline$c_{\text {income }}$ & percentage of taxes on income $(\%$ of $R)$ \\
\hline$S_{\text {reint }}$ & $\begin{array}{l}\text { percentage of the annual fee for annual reintegration for the } \\
\text { renewal of the property capital at the end of its useful life (\% of } \\
\text { construction cost) }\end{array}$ \\
\hline$S_{\text {mai }}$ & $\begin{array}{l}\text { percentage corresponding to the costs of extraordinary } \\
\text { maintenance, administration and insurance ( } \% \text { of construction } \\
\text { cost) }\end{array}$ \\
\hline$c_{\text {property }}$ & percentage corresponding to property tax $(\&$ of $P$ ) \\
\hline$S_{\text {broker }}$ & $\begin{array}{l}\text { percentage corresponding to the costs of marketing the property, } \\
\text { brokerage fees }(\% \text { of } P)\end{array}$ \\
\hline$S_{\text {transfer }}$ & percentage corresponding to the property transfer tax $(\%$ of $P)$ \\
\hline$S_{\text {notary }}$ & percentage corresponding to the notary fees $(\%$ of $P$ ) \\
\hline
\end{tabular}

The coefficient for calculating the reintegration rate $\left(s_{\text {reint }}\right)$ is obtained, as known, with the formula of the final accumulation of the annual constants, delayed and limited. Once the data on the remaining life of the property $\left(v_{r}\right)$ has been obtained, the coefficient is determined according to the discount rate $\left(r_{i}\right)$ using the following equation:

$$
s_{r e \text { int }}=\frac{r_{i}}{\left(1+r_{i}\right)^{v_{r}-1}}
$$

In (5), the expenses relating to the shares of the reintegration and extraordinary maintenance, administration and insurance are calculated as a percentage of the cost of constructing the property, estimated as equal to $2 / 3$ of its market value. The determination of these items does not create any problems due to it normally being revealed by the data collection and measurement or calculation of the magnitudes involved.

Finally, (5) is rewritten in the form of the (6) where the capitalization rate is explained as the unknown of the model.

Particular attention is required in estimating the rates $r_{v}$ and $r_{i}$. The first, which is the annual rate of appreciation or depreciation, in this work is determined by a procedure that uses the time series of property values derived from easily accessible sources. The rate is then defined as equal to the weighted mobile average of the series calculated over a period corresponding to the duration of the property economic cycle, an average of five years. The macro-economic factors which depend on the real estate cycles are designed by Eldestein and Tsang [9]. The definition of the rate $r_{v}$ is objective, differentiated by city and homogeneous area, and reflects the evolutionary trend of the phenomenon. The weighted mobile average, through the use of a linear growth factor, makes it possible to assign greater weight to the information which is more recent and next to the estimation.

The discount rate $\left(r_{i}\right)$ coincides, from a financial perspective, with the internal return rate of the investment. However, in the Ellwood model as well as this new model, it is not obtained as a result of financial analysis, but is introduced by the operator as a well-known fact among the input variables. The unknowns in the equation are consequently reduced to only one, the capitalization rate $\left(r_{c}\right)$. The estimation of $r_{i}$ is actually carried out by the criterion of opportunity cost, assuming as a discount rate, the return rate on an alternative investment to that of the analysis, similar in terms of risk and duration.

In property investments, it is common practice to choose government bonds, as alternative use of the capital. However, the analogy between the property market and public bonds is, in fact, an approximation that involves accurate corrections to the return rate of government bonds in order to obtain the discount rate for the property investment. In conditions of economic stability, it could be argued that the ordinary economic subject who invests money in property, in relation to the similar investment in government bonds which are normally considered risk-free, has a greater appetite for risk as well as managerial capacity to manage the property. It is therefore clear that continuing with this logic would have led to an estimation model that was no different from the others, applied to the indirect estimation of the capitalization rate.

An alternative type of investment, which is similar in terms of risk and duration of the property investment, is that of closed real estate funds. The market, thus, is a share one where there is a variety of financial products associated with a variability of returns, leading to the exclusion of adopting property funds as an alternative investment.

This leads to the idea of using a discount rate related to parameters that are already defined and known by the model, which proposes, through the following conditions:

- the choice of the alternative investment cannot be separated from the expected return for the property being valued, for which the rate of appreciation or depreciation $\left(r_{v}\right)$ is already defined;

- an alternative investment should be treated in relation to the risk that characterizes the expected return and that during the implementation of the model, it is analyzed and expressed through the calculation of the volatility $(\sigma)$ of the investment. An increase in the cost of money and the market presence of other forms of investment with more attractive yields could adversely affect the demand for properties. The capitalization rates could increase greatly if investors require a higher return from the property market in order to compensate for the rising interest rates [3].

For the two conditions mentioned, the calculation of the discount rate $r_{i}$ can be carried out through the choice of a linear combination of the two parameters $\sigma$ and $r_{v}$, which can represent an extreme limit of the actual investment return and risk. Considering that the standard deviation $(\sigma)$, with respect to a normal type distribution, makes it possible to know the range - centred on the average - around which a number of observations falls, and given that the range of $\pm 3 \sigma$ covered $99.73 \%$ of the observed measures, it follows that the discount rate sought can be obtained with the relation:

$r_{i}=r_{v} \cdot(1+3 \cdot \sigma)$. 


\section{CONCLUSIONS}

The indirect estimation of the market value of a property, based on the capitalization of income, has two fundamental assumptions: 1) the equivalence of the market value with the result of the relationship between the ordinary income retractable from the asset and the capitalization rate, 2) the presence of the conditions that allow for the prediction of both the income as well as the rate. It is also essential that the data and information is available in order to determine the rates and incomes.

In the event that there is the possibility to use the rents of properties similar to the one estimated, and thus determine the income to be capitalized, the model outlined in this paper makes the choice of the rate an objective one. When the direct estimation of the rate is not feasible, but it is possible to build a time series of the variations in rates of property values, the model provides a capitalization rate of general validity on the reference area, in order to adjust it when there is the need to take into account the effects of specific factors as well as the intrinsic characteristics of the property estimated.

The objectification of the choice of the rate is due to the transformation, into risk, of the residual uncertainty in some exogenous variables to the balance sheet of the property investment. The operation is carried out through the scenario analysis of Real Options, with the risk being related to the forecast of the future revaluation or devaluation of the property capital. The risk analysis has also allowed for the unique determination of the duration of the investment, corresponding to the availability period of the property. It is up to the estimator whether to use the parameters to estimate the start-up expenses (notary fees and property transfer tax) and management of the property investment.

In the risk analysis, the use of a discrete binomial approach to describe the evolution of the investment over time, simplifies the process and relieves the formalizations that mark a continuous evolutionary model. The latter, as it is known, return the infinite states that the variable can take in each scenario and inside the variation cone, eliminating the gaps present in a discrete model. However, in this work, since the choice of divestiture is generated exclusively by the observation of each of the worst states in each scenario, it was considered not to unnecessarily complicate the model with a continuous approach.

Consistency - with real market values - of the results obtained from the experiments, proves the reliability of the model in practical estimation applications.

\section{REFERENCES}

[1] S.H. Chan, T.V. Grissom and K. Wang, "The Functional Relationship and Use of Going-in and Going-out Capitalization Rates", Journal of Real Estate Research, vol. 5, n. 2, 1990.

[2] Y. Chu and T.F. Sing, "Optimal Timing of Real Estate Investment under an Asymmetric Duopoly", Journal of Real Estate Finance and Economics, n. 34, 2007, pp. 327-345.

[3] P. Conner and L. Youguo, "The complex interaction between real estate cap rates and interest rates", Briefings in Real Estate Finance, vol. 4 n. 3, 2004, pp. 185-197.
[4] J. Cox, S. Ross, and M. Rubinstein, "Option Pricing: A Simplified Approach, Journal of Financial Economics", vol. 7, 1979.

[5] M. Danielson, L. Ekenberg and A. Larsson, "Generalised risk constraints in decision trees with second-order probabilities", Advances in Economics, Risk Management, Political, and Law Science, WSEAS Press, 2012, pp- 376-383.

[6] W. De Ambrogio, Programmazione reticolare, Etas Libri, Milano, 1977.

[7] V. Del Giudice, "La ricerca del saggio di capitalizzazione attraverso i prezzi marginali impliciti”, Studi di economia e diritto, n.3, 1992.

[8] G. De Mare, B. Manganelli, A. Nesticò, "The economic evaluation of investments in the energy sector. A model for the optimization of the scenario analyses", in the $13^{\text {th }}$ International Conference on Computational Science and Its Applications (ICCSA), Lecture Notes in Computer Science, 7972, Springer, Berlin (D), 2013, pp. 359-374.

[9] R.H. Eldestein and D. Tsang, "Dynamic Residential Housing Cycles Analysis", Journal of Real Estate Finance and Economics, n. 35, 2007, pp. 295-313.

[10] L.W. Ellwood, Ellwood Tables for Real Estate Appraising and Financing, Ballinger, Chicago, 1970.

[11] S. Elyassami and A. Idri, "Evaluating software cost estimation models using fuzzy decision trees", Recent Advances in Knowledge Engineering and Systems Science, WSEAS Press, 2013, pp. 243-248.

[12] D.R. Epley, "Reasons to Eliminate the Band-of-Investment Technique for Estimating the Overall Capitalization Rate", Journal of Real Estate Practice and Education, vol. 1, n. 1, 1998.

[13] C. Forte, Elementi di Estimo Urbano, Etass Kompass, Milano, 1968.

[14] P. Gabriela and B. Mircea, "Risk assessment in Public Private Partnerships (PPP) for infrastructure in the recovery after the global crisis", Recent Advances in Risk Management, Assessment and Mitigation, WSEAS Press, 2010, pp. 441-446.

[15] G.D. Jud and D.T. Winkler, "The Capitalization Rate of Commercial Properties and Market Returns", Journal of Real Estate Research, vol. 10, n. 5, 1995.

[16] N. Kerdprasop and K. Kerdprasop, "Discrete decision tree induction to avoid overfitting on categorical data", Recent Researches in Computational Techniques, Non-Linear Systems and Control, WSEAS Press, 2011, pp. 247-252.

[17] S.H. Liao and S.H. Ho, "A fuzzy real options approach for investment project valuation”, Expert Systems with Applications, vol. 38, n. 12, 2011, pp. 15296-15302.

[18] B. Manganelli, P. Morano and F. Tajani, "La valutazione del rischio nell'analisi finanziaria di Ellwood per la stima indiretta di immobili urbani”, Aestimum, n.55, 2009.

[19] A. Yavas and C.F. Sirmans, "Real Options: Experimental Evidence", Journal of Real Estate Finance and Economics, n. 31, 2005, pp. 27-52.

\section{Creative Commons Attribution License 4.0 (Attribution 4.0 International, CC BY 4.0)}

This article is published under the terms of the Creative Commons Attribution License 4.0 https://creativecommons.org/licenses/by/4.0/deed.en US 